\title{
Dexmedetomidine Versus Nitroglycerine for Controlled Hypotension in Head \& Neck Surgery: A Prospective Randomised Clinical Study
}

\author{
Authors \\ Sanjeev Kumar', Chandrakant Prasad ${ }^{2}$, Saurav Shekhar ${ }^{3}$, Ranjeet Rana De ${ }^{3}$, \\ Rakesh Kumar Singh ${ }^{4}$, K. H. Raghwendra ${ }^{5}$ \\ ${ }^{1}$ Addl. Professor, Dept. of Anaesthesiology \& Critical Care Medicine, IGIMS, Patna, India \\ ${ }^{2}$ Junior Resident, Dept. of Anaesthesiology \& Critical Care Medicine, IGIMS, Patna, India \\ ${ }^{3}$ Senior Resident, Dept. of Anaesthesiology \& Critical Care Medicine, \\ ${ }^{4}$ Professor, Dept. of Advanced ENT, IGIMS, Patna, India \\ ${ }^{5}$ Professor, Dept. of Anaesthesiology \& Critical Care Medicine, IGIMS, Patna, India
}

\begin{abstract}
Aim: Present study is aimed to compare Dexmedetomidine with Nitroglycerine for controlled hypotension in head \& neck surgeries in terms of intra-operative blood loss, clearity of surgical field, haemodynamic parameters, post-operative sedation and any adverse events noted.
\end{abstract}

Materials and Methods: After written informed consent and Institutional Ethical Committee approval, 50 patients were randomly allocated into two groups: Dexmedetomidine (Group D) and Nitroglycerine (Group $N)$. After induction of anesthesia, All patients were initially given loading dose of dexmedetomidine ( $1 \mu \mathrm{g}$ $\mathrm{kg}^{-1}$ ) in group-D and equal volume NS in group-N over a period of 10 minutes. Mean arterial pressure (MAP) of all patients were controlled and maintained between 60-65 $\mathrm{mm}$ of $\mathrm{Hg}$ by titrated dose of dexmedetomidine (0.4-0.6 $\left.\mathrm{\mu g} \mathrm{kg}^{-1} \mathrm{~h}^{-1}\right)$ in Group D and Nitroglycerine (0.5-10 $\mathrm{gg} \mathrm{kg}^{-1}$ ) in Group N. Intraoperative blood loss were assessed by surgeon visual bleeding scale and sedation was assessed post operatively in both the groups using Ramsay Sedation score.

Results: Average blood loss in Group D (196.76ml) was significantly less than Group N (232.67ml). Nausea vomiting, tachycardia and shivering were significantly higher in group $N$ where as dryness of mouth and bradycardia was significantly higher in Group D. Sedation score was significantly higher in Group D at 15 mins, 30 mins, 60 mins and 90 mins post-operatively.

Conclusion: Controlled hypotension with dexmedetomidine results in significantly lesser blood loss than with Nitroglycerine, and is associated with prolonged post operative sedation which can be desirable in few patients but leads to increased emergence time.

Keywords-Dexmedetomidine, Nitroglycerine, Head \& Neck Surgery, Controlled Hypotension.

\section{Introduction}

Head and neck region has the most vital vascular channels between cranium and thorax which carries blood from heart to brain and back to cardiac chamber. During this course it has numerous branches in head and neck, hence it is highly vascular region in human body having enormous tendency to bleed intra-operatively which can be life threatening sometimes. It poses major challenge for the anaesthesiologist not only to select the appropriate anaesthetic agents and the way of their delivery but also to maintain contro- 
lled hypotension during surgery to minimize blood loss and achieve bloodless surgical field. Controlled hypotension involves reducing arterial blood pressure $30-40 \%$ below its normal preoperative range or reducing mean arterial pressure (MAP) to $65 \mathrm{mmHg}$ reversibly and maintaining it at that level throughout the surgery. ${ }^{[1]}$ A number of drugs have been studied earlier for this regard including vasodilators like sodium nitroprusside, ${ }^{[2]}$ nitroglycerin $^{[3]}$ and hydralazine; inhalational agents like Isoflurane ${ }^{[4]}$ and sevoflurane; intravenous anesthetics like propofol; beta adrenergic antagonists like esmolol; ${ }^{[5]}$ and $\alpha_{2}$ agonists. Some of the reported disadvantages with the use of these agents include resistance to vasodilators, tachyphylaxis with nitroglycerin, cyanide toxicity with the use of nitroprusside and delayed recovery from anesthesia with the use of high doses of inhaled anesthetics. ${ }^{[6]}$ Nitroglycerine has been frequently compared for controlled hypotension during head \& neck surgery. ${ }^{[3,7]}$ Dexmedetomidine an alpha 2 agonists has also gained wide acceptance for induced hypotension because of its sedative, analgesic and anxiolytic properties. ${ }^{[6,8,9]}$. Here we put forward a comparative study between intravenous Dexmedetomidine and Nitroglycerine for controlled hypotension in head \& neck surgery.

\section{Materials and Methods}

After Written informed consent, this prospective randomized double blind clinical study included 50 patients of ASA status I \& II, of age $>16$ years $\&<50$ years and posted for head and neck surgery under general anaesthesia. Patients with co-morbidities such as hypertension, cardiac disorders, having allergy to study drugs \& posted for major vascular surgeries \& neurosurgical cases were excluded from the study. They were assigned into two groups of 25 each using computergenerated table of random numbers.

Group D - Dexmedetomidine group (loading dose $1 \mu \mathrm{g} \mathrm{kg}^{-1}$ followed by Maintainence dose of 0.4 $0.6 \mathrm{mcg} \mathrm{kg}^{-1} \mathrm{~h}^{-1}$ )
Group N- Nitroglycerine group (loading dose with normal saline and maintenance dose of $0.5-10$ $\mathrm{mcg} \mathrm{kg}^{-1}$ nitroglycerine)

Thorough pre-anesthetic checkup was done on evening before surgery. On the day of surgery patient was premedicated with injection pantoprazole $(40 \mathrm{mg})$ and injection palonosetron $(0.075 \mathrm{mg})$. Upon shifting to operation theater, standard monitors were attached to patients which included electrocardiogram, invasive blood pressure monitoring using radial artery cannulation and $\mathrm{SPO}_{2}$ monitoring. Patients were pre-medicated with inj. Glycopyrrolate $(0.2 \mathrm{mg})$ and inj. Fentanyl $\left(2 \mathrm{mcg} \mathrm{kg}^{-1}\right)$.

Patients were initially given loading dose of dexmedetomidine $1 \mu \mathrm{g} \mathrm{kg}^{-1}$ (Dexmedetomidine was prepared in $50 \mathrm{ml}$ syringe as solution of $2 \mu \mathrm{g} / \mathrm{ml}$ and was given to the patient with the help of syringe pump at the rate of $3 \times$ body weight $\mathrm{ml} /$ hour rate) over a period of 10 minutes or equal volume normal saline in Group $\mathrm{N}$.

After pre-oxygentaion for 3 minutes, patient was induced with injection propofol $\left(2 \mathrm{mg} \mathrm{kg}^{-1}\right)$ and relaxed with injection vecuronium bromide $\left(0.1 \mathrm{mg} \mathrm{kg}^{-1}\right)$. Patients were intubated orally with adequate size cuffed tube. Anaesthesia was maintained with $\mathrm{O}_{2}, \mathrm{~N}_{2} \mathrm{O}$, halothane, vecuronium bromide and controlled mechanical ventilation. MAP of all patients was controlled and maintained between $60-65 \mathrm{mmHg}$ by titrated dose of dexmedetomidine $\left(0.4-0.6 \mathrm{mcg} \mathrm{kg} \mathrm{kg}^{-1}\right.$ in group D, or with Nitroglycerine $\left(0.5-10 \mathrm{mcg} \mathrm{kg}^{-1}\right)$ in group $\mathrm{N}$.

Apart from intra-operative blood loss estimation, all vitals like heart rate, ECG, $\mathrm{MBP}, \mathrm{SPO}_{2}$ \& $\mathrm{ETCO}_{2}$ were monitored. Intraoperative blood loss was assessed by surgeon visual bleeding scale (Table-1) and on the basis of blood volume in suction apparatus and gauze weighing. Sedation was assessed post operatively in both the groups using Ramsay Sedation score.

\section{Blinding}

Two Anaesthesiologists were involved in each case enrolled in this study. One Anaesthesiologist 
was engaged in giving drugs to the patients and to allot random number to the patient in that study. Second Anaesthesiologist was blinded to the study drug given and recorded all data for that case.

\section{Statistical analysis}

Sample size was calculated using Lambda-Willis formula based on data of previous studies. With power of study $80 \%$ and alpha error $5 \%$, the sample size came to 22 for each group. Considering drop outs, 25 patients were recruited in each group. Data were entered into Microsoft Excel spread sheet. SPSS for Windows 21 (SPSS, Chicago, IL, USA) was used for statistical analysis. Continuous variables were analysed with the unpaired t test and categorical variables were analysed with the Chi-Square Test and Fisher Exact Test. $\mathrm{p}<0.05$ was considered statistically significant and $p<0.001$ was highly significant.

Table-1: Intraoperative bleeding scale

\begin{tabular}{|l|l|}
\hline $\begin{array}{l}\text { Bleeding } \\
\text { Score }\end{array}$ & Intra-operative Blood loss \\
\hline 0 & No bleeding \\
\hline 1 & Slight bleeding; no suctioning of blood required \\
\hline 2 & $\begin{array}{l}\text { Slight bleeding; occasional suctioning required. } \\
\text { Surgical field not threatened. }\end{array}$ \\
\hline 3 & $\begin{array}{l}\text { Slight bleeding; frequent suctioning required. } \\
\text { Bleeding threatened surgical field a few seconds } \\
\text { after suction was removed. }\end{array}$ \\
\hline 4 & $\begin{array}{l}\text { Moderate bleeding; frequent suctioning } \\
\text { required. Bleeding threatened surgical field } \\
\text { immediately after suction was removed. }\end{array}$ \\
\hline 5 & $\begin{array}{l}\text { Severe bleeding; constant suctioning required. } \\
\text { Bleeding appeared faster than could be removed } \\
\text { by suction. Surgical field severely threatened } \\
\text { and surgery not possible. }\end{array}$ \\
\hline
\end{tabular}

\section{Results}

The demographic profile of both the groups were comparable as shown in table-2
Table 2: Demographic Profile in both Groups

\begin{tabular}{|c|c|c|c|}
\hline Variable & $\begin{array}{c}\text { Group } \\
\text { D } \\
\end{array}$ & $\begin{array}{c}\text { Group } \\
\mathbf{N}\end{array}$ & $\begin{array}{c}P \text { - } \\
\text { value }\end{array}$ \\
\hline $\begin{array}{l}\text { Mean Age } \\
(\mathrm{yrs})\end{array}$ & $\begin{array}{c}36.2 \pm \\
5.3 \\
\end{array}$ & $\begin{array}{c}37.1 \pm \\
3.1\end{array}$ & 0.325 \\
\hline Weight (kgs) & $\begin{array}{c}53.49 \pm \\
3.35\end{array}$ & $\begin{array}{l}55.35 \\
\pm 3.61\end{array}$ & 0.655 \\
\hline Height (cms) & $\begin{array}{c}162.21 \pm \\
8.35\end{array}$ & $\begin{array}{l}159.35 \\
\pm 9.61\end{array}$ & 0.721 \\
\hline Sex ratio $(M: F)$ & $14: 11$ & $15: 10$ & 0.432 \\
\hline $\begin{array}{l}\text { Duration of } \\
\text { surgery (mins) }\end{array}$ & $\begin{array}{c}90.55 \pm \\
12.82\end{array}$ & $\begin{array}{c}92.27 \pm \\
12.84\end{array}$ & 0.524 \\
\hline
\end{tabular}

The Mean arterial pressure changes in both groups were recorded at regular intervals and results were analysed and tabulated (Table 3). The target mean arterial pressure was achieved in both the groups by titrated infusion of drugs. MAP at different intervals was comparable in both the study groups (figure 1).

Table 3: MAP at different intervals in both the groups

\begin{tabular}{|l|c|c|c|}
\hline Time & Group D & Group N & p-value \\
\hline Basal & $96.43 \pm 5.23$ & $98.43 \pm 5.63$ & 0.426 \\
\hline After intubation & $106.43 \pm 6.33$ & $107.93 \pm 6.29$ & 0.657 \\
\hline 5 mins & $97.43 \pm 5.76$ & $97.68 \pm 7.93$ & 0.998 \\
\hline 10 mins & $86.52 \pm 3.73$ & $84.45 \pm 5.53$ & 0.564 \\
\hline 15 mins & $70.73 \pm 9.13$ & $71.47 \pm 8.64$ & 0.667 \\
\hline 30 mins & $66.67 \pm 4.43$ & $68.83 \pm 4.71$ & 0.554 \\
\hline 45 mins & $65.83 \pm 7.63$ & $66.29 \pm 4.43$ & 0.668 \\
\hline 60 mins & $64.77 \pm 5.23$ & $65.19 \pm 8.73$ & 0.645 \\
\hline 75 mins & $65.49 \pm 5.53$ & $65.47 \pm 3.23$ & 0.887 \\
\hline 90 mins & $64.38 \pm 6.39$ & $65.49 \pm 6.39$ & 0.776 \\
\hline
\end{tabular}

Figure 1: MAP at different intervals in both the groups

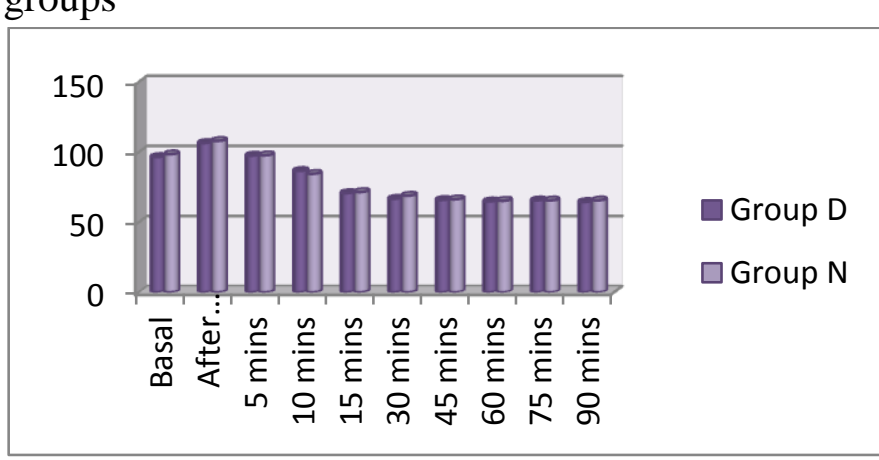

The blood loss was measured by measuring blood loss in suction apparatus and weighing blood soaked gauzes. The average blood loss in group D was $196.76 \mathrm{ml}$ and was less than the average blood loss in group $\mathrm{N}(232.67 \mathrm{ml})$. The difference in blood loss between both groups were 
statistically significant $(\mathrm{p}=0.004)$ (Table 4 \& figure 2)

Table 4: Average blood loss in both the groups

\begin{tabular}{|l|c|c|c|}
\hline Group D & Group N & p-value & Remark \\
\hline $196.76 \mathrm{ml}$ & $232.67 \mathrm{ml}$ & 0.004 & Significant \\
\hline
\end{tabular}

Figure 2: Average blood loss in both the groups.

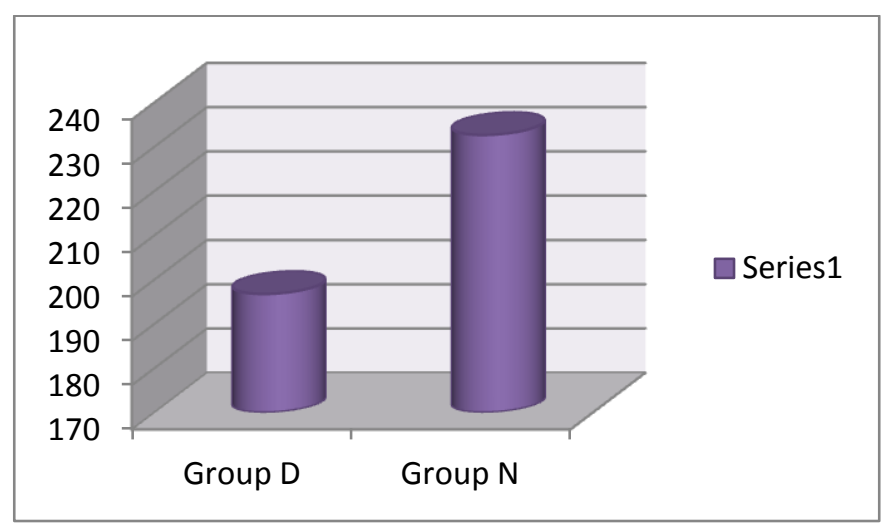

Side effects profiles of both the groups are shown in Table 5. Nausea vomiting, tachycardia and shivering were significantly higher in group $\mathrm{N}$ where as dryness of mouth and bradycardia were significantly higher in group D.

Table 5: Side effect profile of both the groups

\begin{tabular}{|l|c|c|c|}
\hline Side effects & Group D & Group N & p-value \\
\hline Nausea \&Vomiting & 3 & 7 & $<0.001$ \\
\hline Bradycardia & 5 & 1 & $<0.001$ \\
\hline Tachycardia & 1 & 9 & $<0.001$ \\
\hline Dryness of Mouth & 4 & 1 & $<0.001$ \\
\hline Shivering & 3 & 5 & $<0.001$ \\
\hline
\end{tabular}

Sedation score was significantly higher in group D at 15 mins, 30 mins , 60 mins and 90 mins (table 6 \& Figure 3).

Table 6: Ramsay sedation scores of both the groups

\begin{tabular}{|l|c|c|c|}
\hline $\begin{array}{l}\text { Post-Operative } \\
\text { Duration }\end{array}$ & Group D & Group N & p-value \\
\hline $0 \mathrm{~min}$ & $3.1 \pm 0.5$ & $2.9 \pm 1.2$ & 0.432 \\
\hline $15 \mathrm{mins}$ & $2.7 \pm 1.1$ & $1.1 \pm 0.7$ & $<0.001$ \\
\hline $30 \mathrm{mins}$ & $2.6 \pm 0.8$ & $1.0 \pm 0.8$ & $<0.001$ \\
\hline $60 \mathrm{mins}$ & $2.5 \pm 1.1$ & $1.0 \pm 0.6$ & $<0.001$ \\
\hline $90 \mathrm{mins}$ & $2.3 \pm 0.6$ & $1.0 \pm 0.1$ & $<0.001$ \\
\hline $120 \mathrm{mins}$ & $1.3 \pm 0.4$ & $1.1 \pm 0.2$ & 0.334 \\
\hline $150 \mathrm{mins}$ & $1.1 \pm 0.5$ & $1.0 \pm 0.6$ & 0.887 \\
\hline
\end{tabular}

Figure 3: Ramsay sedation scores of both the groups

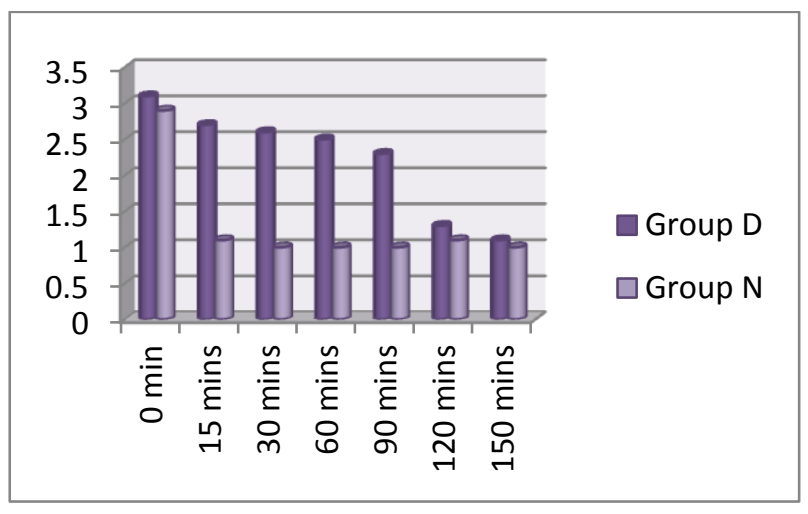

\section{Discussion}

Controlled reduction in blood pressure to such levels so that bleeding is minimal, but at the same time perfusion to the vital organs is wellmaintained is the underlying concept for controlled hypotensive anaesthesia. ${ }^{[10]}$

Dexmedetomidine is a $\alpha_{2}$ selective agonist which leads to inhibition of central sympathetic outflow and stimulation of presynaptic $\alpha_{2}$ adrenoceptors decreasing nor-epinephrine release resulting in reduction in blood pressure, slowing of $\mathrm{HR}$, sedation and analgesia. ${ }^{[11]}$ Its minimal respiratory depressant effect with potent sedative and analgesic effects proves its superiority over opioids and other sedatives. Some of the studies shown that dexmedetomidine decreases the bleeding in surgeries with minimal hemodynamic alteration. ${ }^{[6,8,9,12]}$

Nitroglycerin is a nitric oxide releaser which causes peripheral vasodilation by selectively dilating the venous capacitance vessels with reduction in venous return to the heart resulting in systemic hypotension. But there may be reflex tachycardia partially mitigating the beneficial effects of hypotension. ${ }^{[13]}$

One patient in group D had tachycardia while one in group $\mathrm{N}$ had bradycardia which may be due to other reasons like light plane of anaesthesia, pain or surgical stimulus.

The average blood loss was significantly higher in group $\mathrm{N}$ than in group Dwhich may owe to reflex tachycardia \& prolongation of bleeding time by NTG due to inhibition of platelet aggregation as 
MAP was maintained almost similar in both the drugs by titrated infusion of drugs.

The Ramsay sedation score was significantly higher in Group D than in group $\mathrm{N}$ which is in accordance with Shams et al. ${ }^{[6]}$. The sedative effect of dexmedetomidine is supposed to be mediated through its action in the locus coeruleus. ${ }^{[14]}$ The incidence of postoperative shivering was significantly lower in the group D which is in accordance with Bajwa et al $2012^{[15]}$. Dryness of mouth is the most frequent reported side-effect with dexmedetomidine which is not bothersome and can be easily managed.

\section{Conclusion}

Both nitroglycerine and dexmedetomidine can be used safely for controlled hypotensive surgeries in head \& neck region. Controlled hypotension with dexmedetomidine results in significantly lesser blood loss than with Nitroglycerine, and also that dexmedetomidine is associated with prolonged post operative sedation which can be desirable in some patients but can lead to increased emergence time.

\section{References}

1. Van Aken H, Miller D. Delibrate hypotension. In: Miller RD, editor. Anesthesia. New York, USA: Churchill Livingstone Inc; 2000. pp. 1470-90.

2. Degoute CS, Ray MJ, Manchon M, Dubreuil C, Banssillon V. Remifentanil and controlled hypotension; comparison with nitroprusside or esmolol during tympanoplasty. Can J Anaesth. 2001; 48:20-7.

3. Srivastava U, Dupargude AB, Kumar D, Joshi K, Gupta A. Controlled hypotension for functional endoscopic sinus surgery: Comparison of esmolol and nitroglycerine. Indian J Otolaryngol Head Neck Surg. 2013; 65:440-4.

4. Mandal P. Isofluraneanaesthesia for functional endoscopis sinus surgery. Indian J. Anaesth. 2003; 47:37-40.
5. Degoute CS. Controlled hypotension: A guide to drug choice. Drugs. 2007; 67:1053-76.

6. Shams T, El Bahnasawe NS, Abu-Samra M, El-Masry R. Induced hypotension for functional endoscopic sinus surgery: A comparative study of dexmedetomidine versus esmolol. Saudi J Anaesth. 2013; $7: 175-80$.

7. Guney A, Kaya FN, Yavascaoglu B, Gurbet A, Selmi NH, Kaya S, et al. Comparison of esmolol to nitroglycerine in controlling hypotension during nasal surgery. EAJM. 2012; 44:99-105.

8. Turan G, Dincer E, Ozgultekin A, Uslu C, Akgun N. Comparison of dexmedetomidine, remifentanyl and esmolol in controlled hypotensive anaesthesia. Eur J Anaesthesiol. 2008;25:65-6.

9. Erbesler ZA, Bakan N, Karaoren GY, Erkmen MA. A comparison of the effects of esmolol and dexmedetomidine on the clinical course and cost for controlled hypotensive anaesthesia. Turk J AnaesthReanim. 2013; 41:156-61.

10. Tobias JD. Controlled hypotension in children: A critical review of available agents. Paediatr Drugs.2002; 4:439-53.

11. Hall JE, Uhrich TD, Barney JA, Arain SR, Ebert TJ. Sedative, amnestic and analgesic properties of small-dose dexmedetomidine infusions. Anesth Analg. 2000; 90:699705.

12. Kol IO, Kaygusuz K, Yildirim A, Dogan M, Gursoy S, Yucel E, et al. Controlled hypotension with desflurane combined with esmolol or dexmedetomidine during tympanoplasty in adults: A double-blind, randomized, controlled trial. Curr Ther Res Clin Exp. 2009; 70:197-208.

13. Testa LD, Tobias JD, Pharmacologic drugs for controlled hypotension, $\mathbf{J}$ of ClinAnesth, 7, 1995, 326-337.

14. Guo TZ, Jiang JY, Buttermann AE, Maze M. Dexmedetomidine injection into the 
locus ceruleus produces antinociception.

Anesthesiology. 1996; 84:873-81

15. Bajwa SJ, Gupta S, Kaur J, Singh A, Parmar S. Reduction in the incidence of shivering with perioperative dexmedetomidine: A randomized prospective study. J Anaesthesiol Clin Pharmacol. 2012; 28:86-91. 